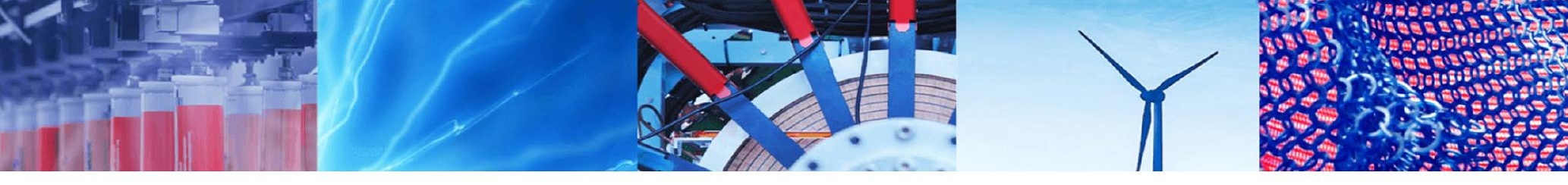

Research Article

\title{
Mechanical and microstructural characterization of aluminum melted with alternative method
}

\author{
F. Severiano ${ }^{1} \cdot$ J. Flores Méndez ${ }^{2,3} \cdot$ M. Salazar-Villanueva ${ }^{4}$
}

Received: 3 November 2019 / Accepted: 31 March 2020 / Published online: 10 April 2020

(c) Springer Nature Switzerland AG 2020

\begin{abstract}
Aluminum is one of the most utilized metals in food, aeronautical, automotive, and architectural industries, due to its intrinsic properties. For this reason, it is important to explore new methods to reuse it. This study was performed to analyze the mechanical and structural properties of aluminum obtained with a homemade oven composed with easily accessible materials. Due to the lack of data about the characteristics of these kinds of materials, its possible applications are unknown. The structural characterization was carried out through optic and electronic microscopy and mechanical testing. The chemical composition was analyzed with energy dispersive spectroscopy. Microscopy images show the presence of cavities in the samples besides the evidence of problems in the solidification phase. The composition analysis shows the presence of Carbon and Magnesium. The mechanical testing showed that the Al obtained had elastic modules and less elongation when compared to commercial Al, which limited the possible uses of this kind of aluminum.
\end{abstract}

Keywords Aluminum $\cdot$ Melting $\cdot$ Homemade oven $\cdot$ Alternative method

\section{Introduction}

Metals are essential, valuable and versatile materials due to their high potential to be recycled and reused. Metals can be used to manufacture cars, airplanes, domestic items such as cutlery, crockery, and even in packaging. For these reasons, scrap metal is valuable for recycling operations. According to the American Iron and Steel Institute (AISI), steel, aluminum, copper, silver, brass, and gold are the most recycled materials on the planet. The most important stage of the Metal Recycling Process is melting. Scrap metal is melted in a large furnace. A considerable amount of energy is used in this stage. Still, the energy required to melt and recycle metals is much less than the energy that is needed to produce metals from their natural state.
Nowadays, the access to information has opened the possibility of accessing new technologies in many branches of science, a clear example is the capacity of melting metals with low cost techniques. This opens the possibility of reusing metals for aluminum with homemade ovens and without the need for gas or electricity. These ovens used to melt metals can be built with easily accessible materials and at low cost. Among these materials, we can find bricks or ceramic containers which have inherent characteristics (high fusion points, high resistance, low thermal conductivity, etc.), which let them implement some melting processes.

Aluminum is the third most common element in the earth. It is a silvery light metal [1]. Technological breakthroughs at the end of the nineteenth century finally allowed aluminum to be melted cheaply, and the price

$\triangle$ F. Severiano, balarama_1@yahoo.com.mx | ${ }^{1}$ CONACYT, Av. Insurgentes Sur 1582, Col. Crédito Constructor, Del. Benito Juárez, CP 03940 Mexico, Mexico. ${ }^{2}$ Benemérita Universidad Autónoma de Puebla-Ciudad Universitaria, Blvd. Valsequillo y Esquina, Av. San Claudio s/n, Col. San Manuel, CP 72570 Puebla, Pue, Mexico. ${ }^{3}$ Tecnológico Nacional de México/I.T., Puebla-División de Estudios de Posgrado E Investigación, Tecnológico Nacional de México/l, Av. Tecnológico No. 420, CP 72220 PueblaMaravillasPuebla, Pue, Mexico. ${ }^{4}$ Facultad de Ingeniería, Universidad Autónoma de Puebla, Apartado Postal J-39, 72570 Puebla, Mexico. 
of metal fell drastically [2, 3]. However, pure aluminum has limited mechanical properties if used for mechanical applications, so aluminum has to be alloyed with other metals like silicon, copper, and magnesium to improve its mechanical properties such as hardness and strength [4]. In industry, aluminum is melted and then goes through different processes, such as casting, pressure die casting, and continuous casting [1]. Aluminum has a lot of applications, from drinks and foils to food wrap, to architectural industry for roofing and windows, and aeronautic and automotive industries, where it is used for lightweight structures and also in art and jewelry design [5-7]. Nowadays, aluminum is one of the most used metals due to its high capacity to be reused [8-13]. Thanks to the low melt temperature of aluminum (approximately $655^{\circ} \mathrm{C}$ or $1215^{\circ}$ $\mathrm{F})$; it is possible to make homemade ovens in which aluminum can be melted to obtain pieces that can be applied in different applications [14]. An important limitation to using this kind of material is the lack of data about its mechanical and structural properties. Thus, experimentally obtained mechanical and structural properties of aluminum samples acquired with a homemade oven are of great importance as initial parameters to know how these ovens can be applied.

The main objective of this study was the mechanical and microstructural characterization of aluminum obtained by methods not involving refined or industrial processes. The oven used in this process was made in a ceramic container surrounded by sand with air intake. The melted aluminum was decanted into sand molds. The aluminum used was totally aluminum cans without a cleaning process before the melting took place, this kind of material is one of the most used and studied to be recycled due to the quantity that is produced [15-18]. The characterizations carried out in this study comprise optic and electron microscopy, energy dispersive spectroscopy (EDS), and mechanical testing. The microscopy images show defects that were associated with problems in the solidification of the samples. The EDS results demonstrate the presence of $\mathrm{C}$ and $\mathrm{Mg}$. The mechanical testing showed that aluminum has a True stress of $636.13 \mathrm{~kg} / \mathrm{cm}^{2}$.

\section{Experimenting}

Aluminum samples were obtained with a homemade oven. Figure 1a shows the schematic diagram (transversal cut) and Fig. $1 \mathrm{~b}$ the oven. No gas or additive was used in the melting of aluminum, only air was supplied with a compressor. The flow of the air was $22 \mathrm{l} / \mathrm{min}$. The combustible used was charcoal. Figure 2a shows the samples obtained by pouring molten aluminum in sand molds with a cylindrical form. Mechanical tension tests were performed using cylindrical probes (see Fig. 2b) according to the specifications of the standard ASTM E8/E8M (Standard Test Methods for Tension Testing of Metallic Materials). The recommended dimensions for the specimens are indicated in Fig. 2b. To carry out the microscopic analysis (optic and electronic), samples with a square cross section of $6 \times 6 \mathrm{~mm}$ were obtained which can be seen in Fig. $2 \mathrm{c}$, these samples were polished with sandpaper (number 200,400 , and 600 ) and alumina of 1.0 and 0.3 microns and a chemical attack with hydrofluoric acid at $5 \%$ during $30 \mathrm{~s}$. The optic microscopy was carried out with an optic PME3 brand Olympus microscope. The stereoscopic microscopy was carried out with a Stemi 508 brand Zeiss microscope.
Fig. 1 a Schematic diagram (transversal cut) of the homemade oven used to melt Al cans $\mathbf{b}$ image taken from the oven while the Al was melted (a)

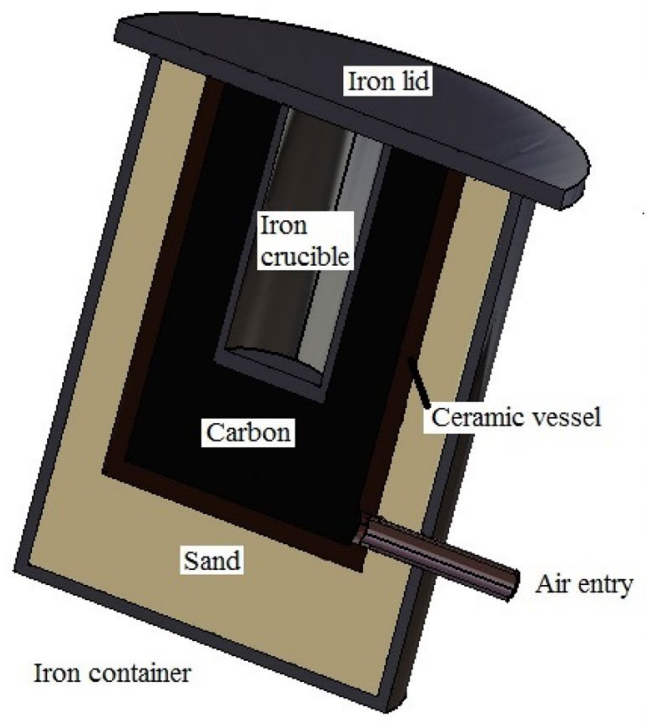

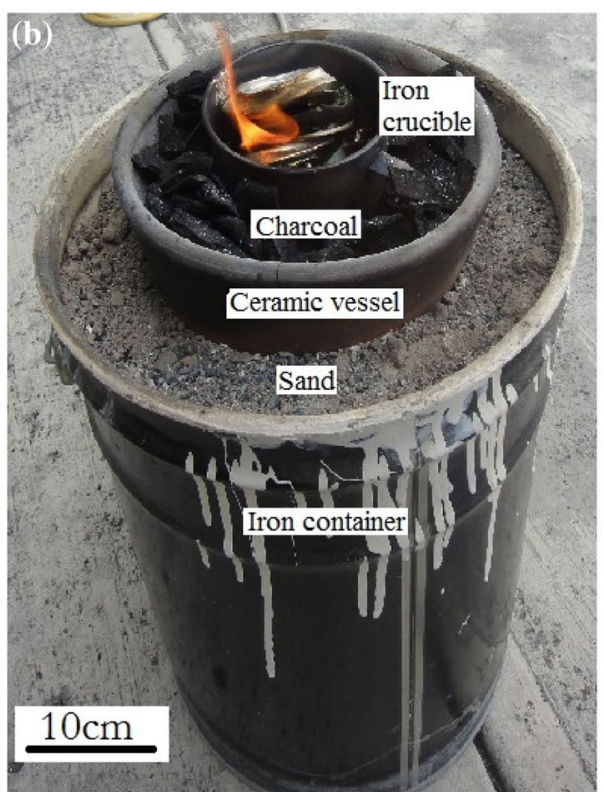



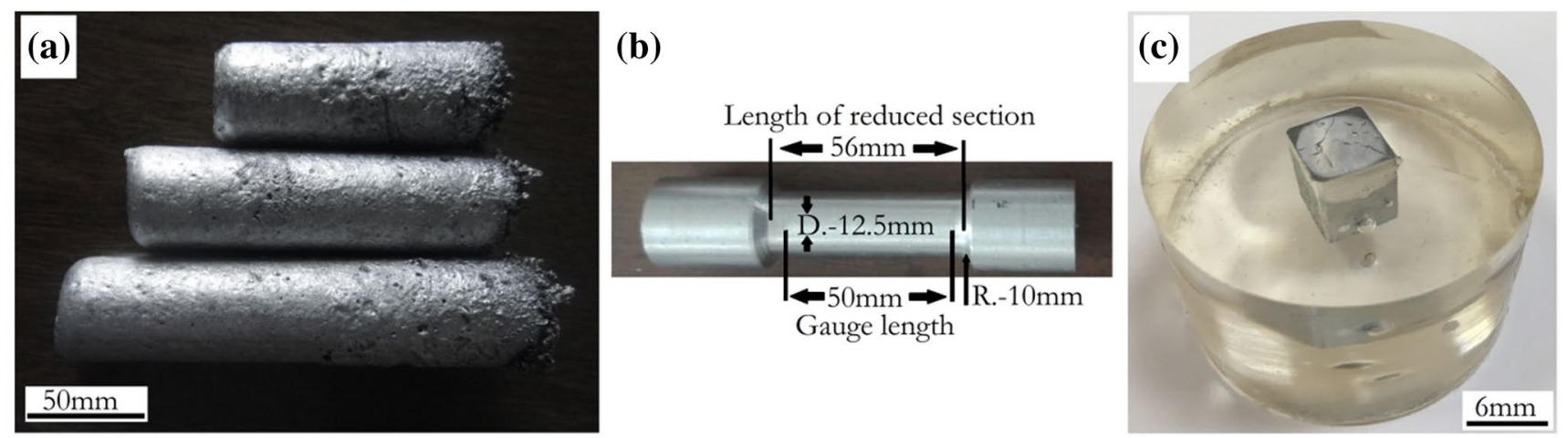

Fig. 2 a Al samples obtained with sand molds. b pieces used in the mechanical testing measures. c Al samples used to make the microscopic analysis

To study the morphology, SEM images were obtained using a SEM model JSM 5400LV brand JEOL microscope. The chemical composition was obtained from the Energy Dispersive spectrometer (EDS) coupled at SEM system. The mechanical testing was carried out in a Autograph AG-IS $100 \mathrm{kN}$ Shimadzu universal testing instrument at a forward speed of $5 \mathrm{~mm} / \mathrm{min}$. FTIR spectra were recorded with a Vertex 70 (Bruker) spectrometer.

\section{Results and discussion}

\subsection{Aluminum microstructure, optic microscopy, and SEM}

Figure 3 shows the images obtained from the transversal cut of the sample of Al of $6 \times 6 \mathrm{~mm}$ showed in the image $2 \mathrm{c}$ with $5,10,15$, and $50 \mathrm{X}$ of magnification. The analysis is focused on the center of the sample. The images of 5 and 10X show many defects on the surface in the form of fissures and cavities. Also, we can see dark zones inside the defects, this is due to the void in the sample, the images also show some formations inside these defects. These kinds of defects, or excessive porosity, are very common in metals without degasser process as was reported by Yang et al. [19] and D. Dhaneswara et al. [4] and are known as shrinkage porosity and are produced by the gases in molten metal, which act as heat insulation and retard heat transfer. The images of 15 and 50X reveal the presence of $\mathrm{Al}$ in the form of little spheres, this is due to an inhomogeneous solidification process. This also explains the fissures and cavities in the Al sample. Similar structures were observed by Lee and Gokhale [20] and are induced by shrinkage porosity formation, which is directly related to gases, pouring temperature, and the sand mold temperature, leading to different local solidification rates.
Figure 4 shows SEM images at a magnification of 100 , 300,550 , and $1000 \mathrm{X}$. With visual observation, the presence of spheres and clusters formed can easily be confirmed with different local solidification rates [20]. The Al sample can be composed of the union of many clusters or spheres. This is more evident in the image that corresponds to $300 \mathrm{X}$, the profile of the spheres or clusters can be seen at the edge of the fissure. We believe that the solidification process is not homogenous and takes place individually in small quantities of $\mathrm{Al}$, which is the origin of the formation of the clusters that we can see in the images. As previously mentioned, the gases in the samples generate thermal insulation which create a gradient temperature and result in an irregular solidification. The image with a magnification of $550 \mathrm{X}$ shows a fissure, we can appreciate the profile of the clusters as well, the depth of the fissure also reveals the presence of clusters. Finally, a close up of $1000 \mathrm{X}$ shows us more clearly how the union of the clusters forms a piece of Al.

\subsubsection{Aluminum microstructure, post mechanical testing}

Figure 5 shows the images of stereoscopic microscopy taken from a piece of a cylindrical sample after the mechanical testing. The inner structure of the Al is a granular structure, close-up images clearly show us the "spheres" or "drops" of Al, which are formed due to the temperature insulation and time of solidification of the sample.

\subsection{EDS analysis}

Figure 6 shows the EDS spectra, which reveals the presence of $\mathrm{C}, \mathrm{O}$, and $\mathrm{Mg}$. The $\mathrm{C}$ is attributed to the contamination in the sample, this happens during the melt process, the ashes enter the crucible because there is a space between the crucible and the iron lid. The $\mathrm{O}$ is due to the oxidation of the sample when it is exposed to the environment, also 

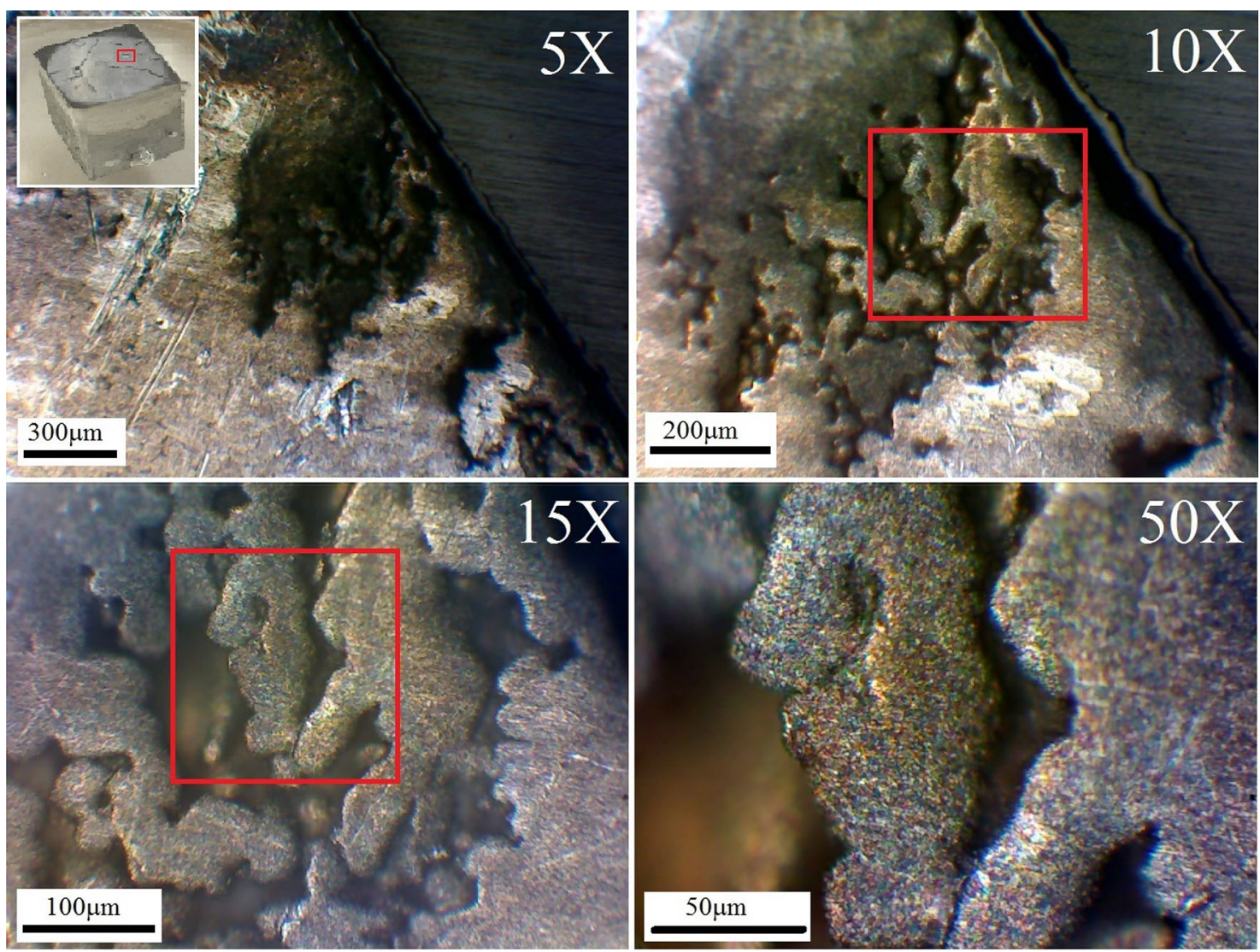

Fig. 3 Optic microscopy with different magnifications. The different images show the defects in the surface of the Al samples obtained. The inset shows the zone analyzed in this study

can be due to the gases that are the origin of the shrinkage porosity [19]. The results suggest that the material recycle in this work was $3 \mathrm{XXX}$ series aluminum alloy due to the presence of manganese, element used in this kind of alloy [21]. It has good mechanical properties and exhibits good weldability. It is one of the most common alloys of aluminum for general purpose use. Finally, $\mathrm{Mg}$ is due to the alloys of Aluminum used for beverage cans.

\subsection{Mechanical testing}

Figure 7 shows a representative stress-strain curve obtained from the mechanical testing of the cylindrical samples (sample 4). In this curve, different phases during mechanical testing were marked. Table 1 summarized the data obtained from the study and also shows mean and standard deviation. The characteristic curve shows a short proportional limit, this indicates that the sample has a low resistance to stress, this can be due to the defects (fissures) in the structure. The region of the uniform plastic deformation shows that the sample has a long resistance to fracture or deformity, this can be due to the empty space in the sample that allows the rearrangement of the material.
The necking zone is short and shows a low resistance to the stress before fracturing. Table 2 shows some parameters that were calculated to be compared with commercial Al data. It is important to observe the low tensile properties from the Al samples obtained, for example, the elastic module estimated $(0.5 \mathrm{GPa})$ in comparison with the reported value from Al-3XXX alloy (70-80 GPa) [22], this is due to the quantity of fissures in the sample which reduces its resistance to stretching. On the other hand, the percent of elongation (3.53\%) also shows a decrease when it is compared with the reported value (10\%) [22] and also is due to a loss of stretching capacity. These results demonstrate that pieces obtained with the process of low costs did not show the same characteristics of Al as cast [23-25]. This is due to the temperatures and the recipients used to melt $\mathrm{Al}$, which generate problems in the solidification process.

The trapped air or empty space in the sample was calculated with the difference in densities. Knowing the density of $3 X X X$ series aluminum alloy $\left(2.7 \mathrm{~g} / \mathrm{cm}^{3}\right)$ [22] and the mass and volume of the sample obtained, it can be determined the air content in the structure. The result was that the volume and the mass of the melted sample

\section{SN Applied Sciences




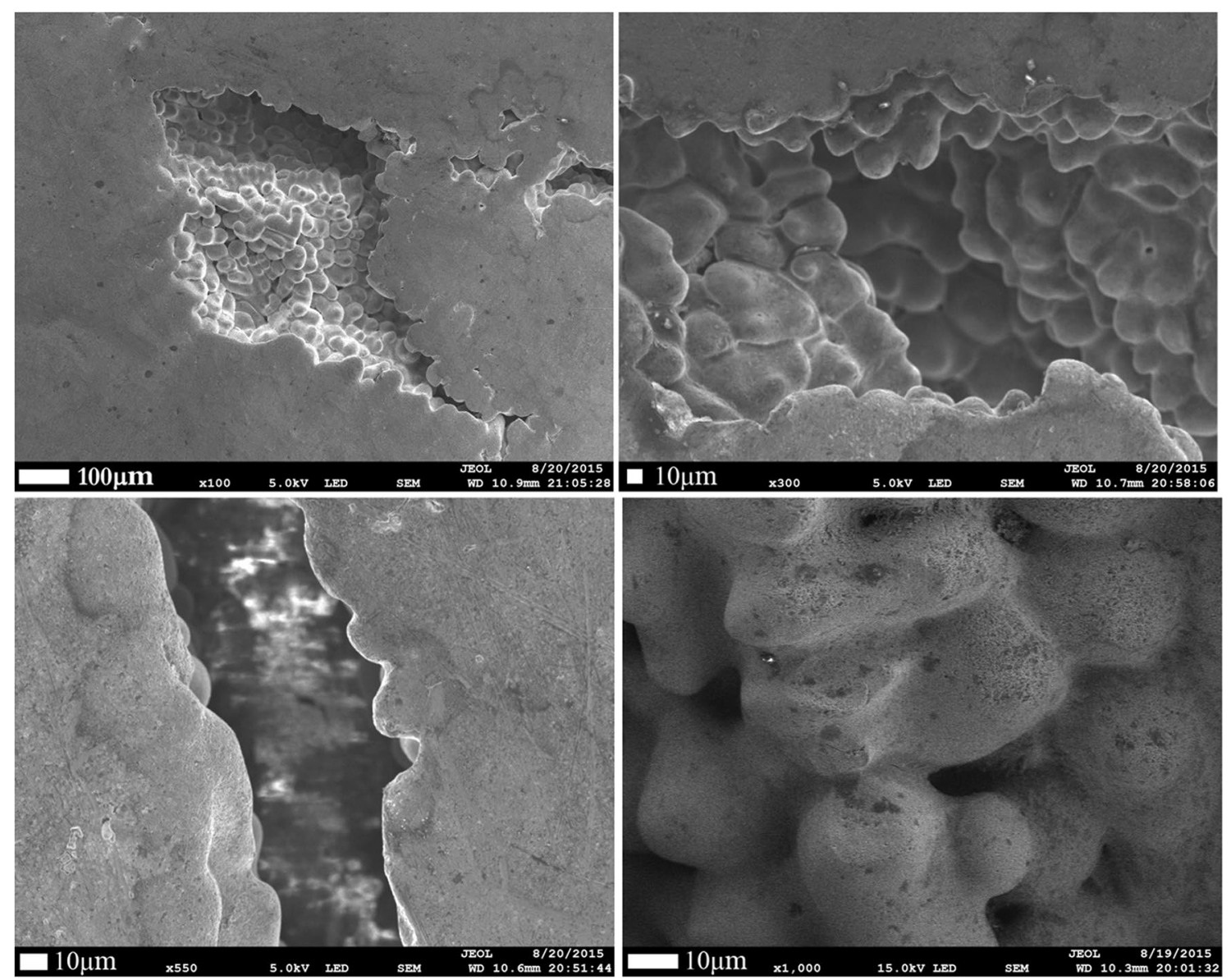

Fig. 4 SEM images that show the presence of clusters in the Al samples
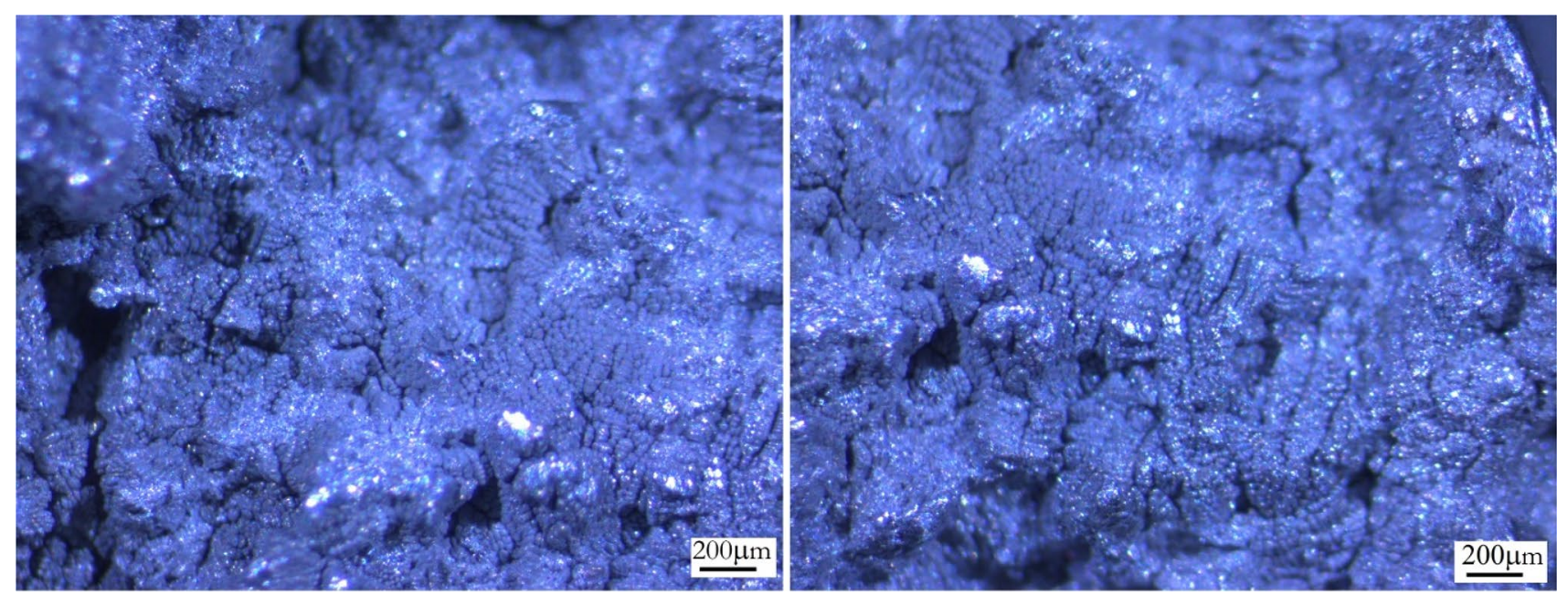

Fig. 5 Analyzed sample through stereoscopic microscopy after the mechanical testing 


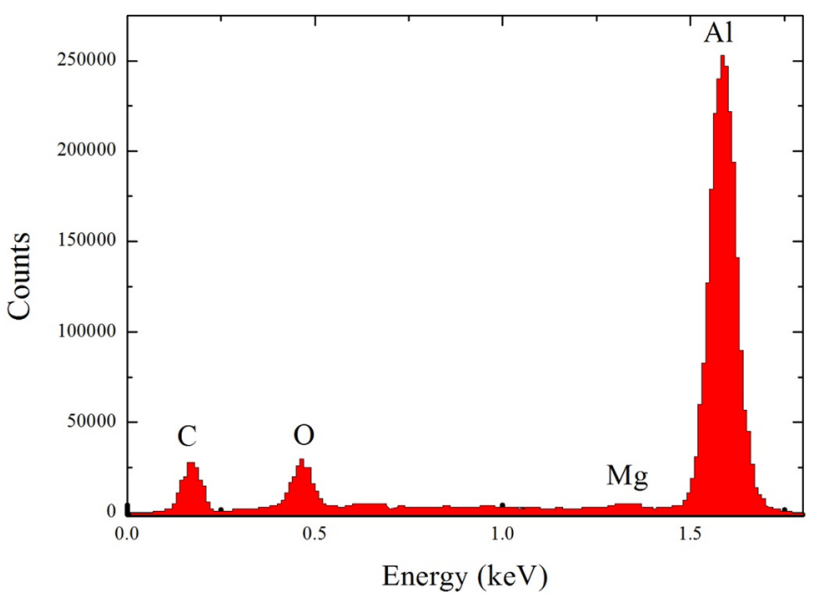

Fig. 6 EDS spectra that show the presence of $\mathrm{Mg}$ and $\mathrm{C}$ in the $\mathrm{Al}$ samples

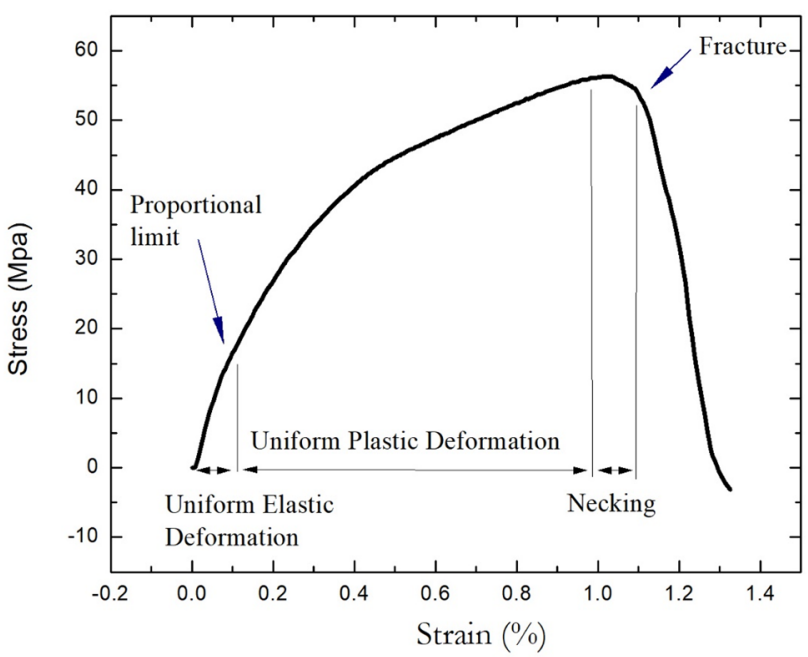

Fig. 7 Stress-strain curve from Al sample. The principal points of the curve are marked in the image

Table 1 Data obtained from the mechanical testing, also show the mean and the standard deviation

\begin{tabular}{llll}
\hline Sample & Maximum force $(\mathrm{N})$ & $\begin{array}{l}\text { Maximum ten- } \\
\text { sion }\left(\mathrm{N} / \mathrm{mm}^{2}\right)\end{array}$ & $\begin{array}{l}\text { Maximum } \\
\text { displacement } \\
(\mathrm{mm})\end{array}$ \\
\hline 1 & 7881.25 & 70.8616 & 2.124 \\
2 & 5556.25 & 49.9572 & 0.742 \\
3 & 7381.25 & 66.3661 & 1.757 \\
4 & 6362.50 & 56.2569 & 0.896 \\
Mean & 6795.31 & 60.86 & 1.37 \\
SD & 1040.06 & 9.49 & 0.66 \\
\hline
\end{tabular}

were $5.34 \mathrm{~cm}^{3}$ and $11.6 \mathrm{~g}$, respectively. So the density was $2.17 \mathrm{~g} / \mathrm{cm}^{3}$. Relating the two densities we can calculate the air volume in the sample, obtaining the $20 \%$ of air or empty space.

\subsection{Fourier transforms infrared spectroscopy (FT-IR) analysis}

Figure 8 shows FTIR spectra from Al sample after the mechanical analysis. The assignation of peaks and bands was as follows: the broadband at $3200-3700 \mathrm{~cm}^{-1}$ is its characteristic of $-\mathrm{OH}$ stretching vibration that is bonded to $\mathrm{Al}^{3+}$. The peak at $1029 \mathrm{~cm}^{-1}$ is typically for $\gamma$-alumina due to Al-O vibration mode [26]. The band between $1000 \mathrm{~cm}^{-1}$ and $485 \mathrm{~cm}^{-1}$ confirms the $\gamma$-phase of alumina, and the shoulder at $912 \mathrm{~cm}^{-1}$ is assigned to the bending vibrations of Al-O bond. The peak at $1843 \mathrm{~cm}^{-1}$ belongs to the nonsymmetric vibration absorption of $\mathrm{C}=\mathrm{O}$, and the band between 1410 and $1890 \mathrm{~cm}^{-1}$ could be attributed to the antisymmetric stretching vibration absorption of $\mathrm{C}=\mathrm{O}$. In addition, there is a $\mathrm{C}-\mathrm{H}$ symmetric stretching vibration peak at $2952 \mathrm{~cm}^{-1}$ [27]. These results support the presence of impurities of carbon as shown in EDS analysis in the aluminum structure.

\section{Conclusions}

Al samples were obtained with a homemade oven. The microscopic characterizations show that the samples have defects (fissures and cavities). These kinds of defects or excessive porosity are known as shrinkage porosity and are produced by the gases in the molten metal, which act as heat insulation and retard heat transfer. We can see "spheres" or "drops" in the Al structure. We propose that these forms are due to different times of solidification. In other words, molten Al solidifies upon contact with the sand mold, thus the spherical shapes observed in the structure are formed. This suggests that the temperature reached in the homemade oven is barely superior to the fusion temperature of the Al. EDS analysis shows the presence of $\mathrm{Al}, \mathrm{C}$, and $\mathrm{Mg}$. Due to the presence of $\mathrm{C}$ in the structure, we can say that this process is a "dirty process."The IR results support the presence of impurities of carbon in the aluminum structure. The mechanical testing shows the low elastic module and percent of elongation, which limits the possible uses of this kind of pieces. 
Table 2 Calculus of different parameters of the sample with the data obtained from mechanical testing

\begin{tabular}{|c|c|c|c|}
\hline Parameter & Equation & Where & Result \\
\hline True stress & $T_{S}=\frac{F}{A}$ & $\begin{array}{l}\text { Ts }=\text { True stress in } \mathrm{Kg} / \mathrm{cm}^{2} \\
\mathrm{~F}=\text { Force applied in } \mathrm{kg} \\
\mathrm{A}=\text { Actual area at which the force is applied in } \mathrm{cm}^{2}\end{array}$ & $635.49 \mathrm{~kg} / \mathrm{cm}^{2}$ \\
\hline Percent of elongation & $\% E=\left(\frac{F I-O I}{T I}\right) 100$ & $\begin{array}{l}\% \mathrm{E}=\text { Elongation in } \% \\
\mathrm{FI}=\text { Final length in } \mathrm{cm} \\
\mathrm{Ol}=\text { Original length in } \mathrm{cm} \\
\mathrm{TI}=\text { Test length in } \mathrm{cm}\end{array}$ & $3.53 \%$ \\
\hline Percent area reduction & $\% R=\left(\frac{O a-F a}{O a}\right) 100$ & $\begin{array}{l}\% \mathrm{R}=\text { Percent Area Reduction } \\
\mathrm{Oa}=\text { Original area in } \mathrm{cm}^{2} \text { (before test) } \\
\mathrm{Fa}=\text { Final area in } \mathrm{cm}^{2} \text { (after test) }\end{array}$ & $3.18 \%$ \\
\hline Elastic module & $E=\frac{E p}{\epsilon}$ & $\begin{array}{l}\mathrm{E}=\text { elastic module in } \mathrm{Kg} / \mathrm{cm}^{2} \\
\mathrm{Ep}=\text { proportional limit effort } \\
\epsilon=\text { Unit strain in } \mathrm{mm} / \mathrm{mm} \text { o } \mathrm{cm} / \mathrm{cm} \text { dimensionless }\end{array}$ & $5159.31 \mathrm{~kg} / \mathrm{cm}^{2}$ \\
\hline Proportional limit effort & $E p=\frac{L}{A}$ & $\begin{array}{l}\mathrm{Ep}=\text { proportional limit effort in } \mathrm{kg} / \mathrm{cm}^{2} \\
\mathrm{~L}=\text { Load applied at the limit of proportionality in } \mathrm{Kg} \\
\mathrm{A}=\text { Cross-sectional area in } \mathrm{cm}^{2}\end{array}$ & $149.62 \mathrm{~kg} / \mathrm{cm}^{2}$ \\
\hline True strain & $\varepsilon=\int \frac{d l}{l}=\ln \left(\frac{l}{l_{o}}\right)=\ln \left(\frac{A_{0}}{A}\right)$ & $\begin{array}{l}\epsilon=\text { Unit strain in } \mathrm{mm} / \mathrm{mm} \text { o } \mathrm{cm} / \mathrm{cm} \text { dimensionless } \\
A_{o} I_{o}=\text { Original area or length in } \mathrm{cm} \text { ó } \mathrm{m} \\
A, I=\text { Area or length from the test in } \mathrm{cm} \text { ó } \mathrm{m}\end{array}$ & 0.029 \\
\hline
\end{tabular}

Data used to calculated different parameters of the samples: Diameter (before testing) $1.2 \mathrm{~cm}$, Diameter (after testing) $1.18 \mathrm{~cm}$, Area (before testing) $1.13 \mathrm{~cm}^{2}$, Area (after testing) $1.09 \mathrm{~cm}^{2}$

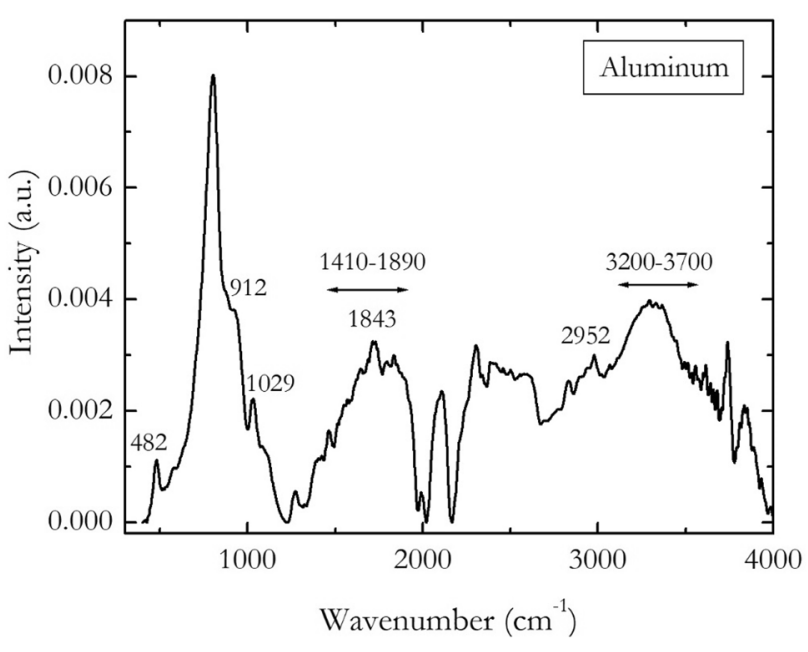

Fig. 8 IR spectra taken from a Al sample after the mechanical analysis

Acknowledgments F. Severiano thanks CONACYT for its support through project 165 of cátedras CONACYT.

\section{Compliance with ethical standards}

Conflict of interest The authors declare that they have no competing interest.

\section{References}

1. Leitner M, Leitner T, Schmon A, Aziz K, Pottlacher G (2017) Thermophysical properties of liquid aluminum. Metall Mater Trans A 48:3036-3045

2. Logozar K, Radonjic G, Bastic M (2006) Incorporation of reverse logistics model into in-plant recycling process: a case of aluminium industry. Resour Conserv Recycl 49(1):49-67

3. Zhou B, Yang Y, Reuter MA, Boin UMJ (2006) Modelling of aluminium scrap melting in a rotary furnace. Miner Eng 19(3):299-308

4. D Dhaneswara, JF Fatriansyah, R Ramadhan, and A Ashari, (2019) The effect of melting temperature aluminum metal casting using mixed degasser based sodium fluoride and sodium nitrate MATEC Web of conferences 269.

5. Evancho JW, Kaufman JG (1977) New 6XXX-series alloys for auto body sheet. Aluminum 53:609

6. Altenpohl DG (1998) Aluminum, technology, applications, and environment, a profile of a modern metal, 6 th edn. TMS, Washington, pp 360-364

7. Troeger LP, Starke EA Jr (2000) Microstructural and mechanical characterization of a superplastic $6 x x x$ aluminum alloy. Mater Sci Eng 277:102-113

8. Campbell MC (1996) Non-ferrous metals recycling: a complement to primary metals production. International Council on Metals and the Environment (ICME), Canada, pp 3-8.

9. Henstock MF (1996) The recycling of non-ferrous metals. International Council on Metals and the Environment (ICME), Canada, pp 9-17

10. Gronostajski J, Matuszak A (1999) The recycling of metals by plastic deformation: an example of recycling of aluminium and its alloys chips. J Mater Process Technol 92:35-41

11. Gronostajski J, Marciniak H, Matuszak A (2000) New methods of aluminium and aluminium-alloy chips recycling. J Mater Process Technol 106:34-39

12. Samuel $M(2003)$ A new technique for recycling aluminium scrap. J Mater Process Technol 135(1):117-124 
13. Fogagnolo JB, Ruiz-Navas EM, Simón MA, Martinez MA (2003) Recycling of aluminium alloy and aluminium matrix composite chips by pressing and hot extrusion. J Mater Process Technol 143-144:792-795

14. Kaufman JG (2016) Fire resistance of aluminum and aluminum alloys and measuring the effects of fire exposure on the properties of aluminum alloys, chapter 1. ASM International, Materials Park, pp 1-9

15. Peterson RD (1990) Effect of salt flux additives on aluminum droplet coalescence. In: Proceedings of second international symposium on recycling of metals and engineering materials. Warrendale, pp 69-84

16. Roy RR, Sahai Y (1998) The role of salt flux in recycling of aluminum. In: Welch B (ed) Light metals. The Minerals Metals and Materials Society, Warrendale, pp 1237-1243

17. Utigard TA, Friesen K, Roy RR, Lim J, Silny A, Dupuis C (1998) The properties and uses of fluxes in molten aluminum processing. $J$ Min Met Mater Soc 50(11):38-43

18. Ye J, Sahai Y (1996) Interfacial behavior and coalescence of aluminum drops in molten salts. Mater Trans JIM. 37(2):175-180

19. Yang H, Guo Z, Yang H, Fu Z, Pu Z, Xiong S (2019) Effect of vacuum on porosity and mechanical properties of high-pressure die-cast pure copper. Res Dev 16(4):232-237

20. Lee SG, Gokhale AM (2006) Formation of gas induced shrinkage porosity in Mg-alloy high-pressure die-castings. Scripta Mater $55: 387-390$
21. Shriwas AK, Kale VC (2016) Impact of aluminum alloys and microstructures on engineering properties. IOSR J Mech Civil Eng 13(3):16-22

22. AZoM, Aluminum/Aluminium 3003 Alloy (UNS A93003). https:// www.azom.com/article.aspx?ArticleID $=6618$

23. Mabuchi M, Higashi K, Langdon TG (1994) An investigation of the role of a liquid phase in AlCuMg metal matrix composites exhibiting high strain rate superplasticity. Acta Metall Mater 42(5):1739-1745

24. Nieh TG, Imai T, Wadsworth J, Kojima S (1994) High strain rate superplasticity of a powder metallurgy $\mathrm{SiC}$ particulate reinforced 6061 Al composite. Scripta Metall Mater 31(8):1685-1690

25. Lee SH, Saito Y, Sakai T, Utsunomiya H (2002) Microstructures and mechanical properties of 6061 aluminum alloy processed by accumulative roll-bonding. Mater Sci Eng A 325:228-235

26. Xu B, Yang Y, Xu Y, Han B, Wang Y, Liu X, Yan Z (2017) Synthesis and characterization of mesoporous Si-modified alumina with high thermal stability. Microporous Mesoporous Mater 238:84-89

27. Xie Z, Guan W, Ji F, Song Z, Zhao Y (2014) Production of biologically activated carbon from orange peel and landfill leachate subsequent treatment technology. J Chem. https://doi. org/10.1155/2014/491912

Publisher's Note Springer Nature remains neutral with regard to jurisdictional claims in published maps and institutional affiliations. 